\title{
Farm-level adaptation to climate change: the case of the Loam region in Belgium
}

\author{
Julia de Frutos Cachorro* Anne Gobin ${ }^{\dagger} \quad$ Jeroen Buysse ${ }^{\ddagger}$
}

July 17, 2018

Article published in Agricultural Systems (2018)

DOI: $10.1016 /$ j.agsy.2018.06.007

\begin{abstract}
Few studies have addressed the topic of farmers' adaptation to climate change from a multidisciplinary perspective, because of the difficulty in assessing their impacts. In view of the growing concern in the agricultural sector on this issue, we analyzed farmlevel adaptation through arable land-use changes in the specific case of the Loam region in Belgium. With this aim, we used an agro-economic model which considered 20-year series of current and projected simulated yields with and without considering additional farming practices to reduce crop stress, such as irrigation and soil and water conservation techniques. Agronomic results show that climate change will negatively affect summer crop yields, particularly sugar beet and potatoes. However, we also show that adaptation to climate change through land-use changes can compensate for crop yield losses and lead to utility gains. These are obtained by reducing the share of land allocated to summer crops and barley and by increasing the surface allocated to less vulnerable crops such as winter wheat. Finally, irrigation practices would not
\end{abstract}

*Departament de Matemàtica Econòmica, Financera i Actuarial and BEAT, Universitat de Barcelona, Avinguda Diagonal 690, 08034 Barcelona, Spain. E-mail: j.defrutos@ub.edu (Corresponding author.)

${ }^{\dagger}$ Flemish Institute for Technological Research (VITO), Boeretang 200, $2400 \mathrm{Mol}$, Belgium.

${ }^{\ddagger}$ Department of Agricultural Economics, Faculty of Bioscience Engineering, Ghent University, Coupure Links 653, 9000 Ghent, Belgium. 
be justified in the Loam region under climate change, since their use would incur important financial costs for farmers.

Keywords: farmers' adaptation, crop choices, irrigation, climate change, agro-economic model.

JEL: C60, Q12, Q54 


\section{Introduction}

Scientific climate change reports (IPCC $(2007,2008,2014)$ [21] [22] [23]) predict important economic and environmental impacts on human activities. Agriculture is especially sensitive to climatic conditions and is one of the most vulnerable sectors to climate change (Bradshaw et al. (2004) [5]). In particular, changes in precipitation, temperature, extreme weather events and $\mathrm{CO}_{2}$ levels are expected, which are not uniform across European regions (Trnka et al. (2011) [51]; Iglesias and Garrote (2015) [19]) and may impact on agricultural activities in EU regions in different ways depending on their adaptive capacity. In this context, research on adaptation becomes necessary in order to mitigate climate change impacts on agriculture.

Although there is relatively recent literature about farmers' adaptation strategies for climate variability and change, a large number of studies have dealt with the topic by considering different adaptation measures. These include farm practices such as irrigation and soil conservation techniques (e.g. Finger et al. (2011) [11]), land-use (e.g. Kaiser et al. (1993) [30]; Klein et al. (2013) [31]; Liu et al. (2016b) [33]), technology adoption (e.g. Foudi and Erdlenbruch (2012) [12]), and financial support (e.g. Berrang-Ford et al. (2011) [4]) among others. While most studies consider gradual climate change, i.e. long-term changes to average climate conditions, agriculture is particularly vulnerable to extreme weather conditions ${ }^{1}$ such as more frequent droughts and deviation from 'normal' growing season conditions (Smit and Skinner (2002) [49]).

For this reason, in recent years, an important number of studies have addressed the topic of extreme weather impacts on crop performance and yields (e.g. Thornton et al. (2014) [50]; Trnka et al. (2014) [53]; Powell and Reinhard (2016) [41]; Harrison et al. (2016)[16]; Lesk et al. (2016) [29]), mostly focusing on drought (White et al. (2011) [57]) and heat stress (Liu et al. (2016a) [32]; Deryng et al. (2014) [8]). In addition, literature about adaptation to extreme events due to climate change has attracted considerable attention (see for example Olesen et al. (2011) [37] and Trnka et al. (2014) [53] for European

\footnotetext{
${ }^{1}$ Extreme weather events are meteorological phenomena that are at the extremes of the historical distribution (WMO (2011) [56]).
} 
studies). However, existing research has focused mainly on crop-level adaptation, while more research is still needed on measures, costs and adoption rates for adaptation at farm level, as argued by Mandryk et al. (2017) [35].

In this paper, we concentrate on farmers' adaptation to climate change impacts in the Loam region of Belgium, as well as on farm-level utility outputs from these adaptations ${ }^{2}$. The Loam region, situated in Central Belgium, was formed on quaternary loess and has the best soils for arable agriculture in Belgium. Climate models predict a shift in climate conditions to drier summers and wetter winters in Belgium by the end of this century. Warmer temperatures could positively impact some crops such as winter wheat (Belgian National Climate Comission (2010)[18]). However, the expected increase in extreme events ${ }^{3}$ such as heatwaves and longer drought periods, may have a negative influence on summer crops such as potatoes (cf. [18]; Gobin (2012) [14]). A large number of studies in the Netherlands (e.g. Mandryk et al. (2017) [35]; Schaap et al. (2013) [45]), where climate conditions are similar, have gone further in assessing the economic impact of crop and farmlevel adaptations and have shown that a shift to more winter wheat in systems dominated by root crops could be an efficient strategy in order to maintain economic and soil quality objectives. In addition, drip irrigation for potatoes could be a good option to counteract the potential impact of heatwaves. Indeed, farmers' adaptation measures such as changes in crop choices and farming practices such as irrigation and soil management are mainly expected to mitigate climate change impacts in Central and Western Europe (see Olesen et al. (2011) [37] for an european reviews). The aim of this paper is to analyze farmers' adaptation through land-use changes to climate change, with and without considering additional farm practices such as irrigation and soil and water conservation techniques.

Different methods are employed in the literature to study the general topic of adaptation to climate variability and change, e.g. anthropological approaches (Jahangir Kabir et al. 2017 [24]), econometric models (see Seo and Mendelsohn (2008) [48]; Mu et al. (2013)

\footnotetext{
${ }^{2}$ As explained in Roco et al. (2014) in a similar study, according to the theory of utility maximization, the individual farmer adopts a new practise (or adaptation measure) only if the expected utility is greater than the utility associated with the current practise.

${ }^{3}$ For a definition of relevant extremes weather conditions for different arable crops and a meta-analysis on records in Belgium, we refer to Gobin (2017) [15].
} 
[36]) and integrated models (see for example Kaiser et al. (1993) [30] for an agro-economic model and Schaap et al. (2013) [45] for a crop growth model, combined with a participatory approach) at different levels of decision-making (global, regional and farm levels). Several studies advocate interdisciplinary modeling approaches (e.g. Falloon and Betts (2010) [9]; Reidsma et al. (2015) [42]; Antle and Stöckle (2017) [3]). Reidsma et al. (2015) [42] argued that integrated approaches provide added value compared to disciplinary research as they allow a better understanding of the complexity of the system. In addition, Jahangir Kabir et al. (2017) [24] claim that understanding local perspectives, farm-level adaptation and risk management strategies is critically important for supporting decision making.

In this study, we focused on the use of an agro-economic model at the farm level. Firstly, a dynamic crop model (REGCROP) was used to build yield time series under current and projected climatic conditions (Gobin (2010, 2012) [13], [14]), which used a stochastic weather generator (LARS-WG) and incorporated the effect of drought and heat stress on crop growth. Yield simulations were subsequently used as inputs to the economic component of the model - a Positive Mathematical Programming (PMP) framework which took into account risk in farm decision-making. Some authors have already used this methodology for economic assessments (e.g. Paris and Arfini (2000) [38]; Cortigiani and Severini (2012) [7]; Petsakos and Rozakis (2015) [40]). We have chosen for the approach of Cortignani and Severini in [7], which estimates the absolute risk aversion coefficient along with the non-linear cost function and the resource shadow price with a maximum entropy program. However, we fixed the resource shadow price to the the rental price of the land in the study area in order to avoid the criticized first step of traditional PMP models (cf. Heckelei and Wolff (2003) [17]).

In addition, we adapted the Cortignani and Severini model (cf. [7]) to simulate land allocation of a hypothetical arable farm in the Loam region. We consider our results to have strong implications at the regional scale, since crop acreages and yields represent those of the region. Overall, the main goal of our study is to investigate what land-use allocations are consistent with maximizing farm-level utility over a 20-year period with projected climate change series, and selected adaptation measures. More specifically, simulated crop impacts, land-use changes and farmers' utility outputs, with and without land-use adapta- 
tion, are compared for different scenarios, i.e. under current and future projected climatic conditions, with and without considering the application of additional measures to reduce crop stress, such as irrigation and soil and water conservation techniques. Finally, the impact of important economic factors on model outputs such as the uncertainty about future crop prices under climate change is also analyzed.

\section{An agro-economic model of land-use choice}

The general methodology consisted of the use of an integrated approach with agronomic and economic components. It has been extensively shown that farmers performed differently depending on their main individual objectives (Mandryk et al. (2017) [35]), which in most of the surveys (see Mandryk et al. (2014) [34] for an example) can be classified into biophysical (e.g. crop performance, soil quality...) and economic goals (e.g. maximizing gross margin of crops per hectare). Economic objectives should then be included in conjunction with biophysical system analysis, to improve efficiency in farm-level decisionmaking, which justified the multidisciplinary approach proposed here.

Returning to the description of our agro-economic model, the agronomic component was firstly used to provide crop yield data and water requirements for a 20-year period under current and projected climatic conditions. These agronomic data served as inputs of the economic component of the model. In particular, crop yield data are injected in the economic model through the average gross margins and the variance-covariance matrix of unitary gross margins, while crop water requirements are included in irrigation costs, thereby representing system variability over time. The economic component consisted of a two-stage Positive Mathematical Programming model, in which we firstly determined relevant parameters of risk aversion and quadratic costs of the farmer objective function, by using a maximum entropy calibration program, based on land-use observations in the study area. Subsequently, we used a single static optimization model that maximizes the farmer expected utility ${ }^{4}$ over a 20 -year period, to obtain crop specific land allocation and

\footnotetext{
${ }^{4}$ Expected utility theory has been extensively validated in the literature when facing problems of decision-making under uncertainty. As argued by Heckelei and Wolff in [17], expected utility models
} 
corresponding farm-level expected utilities under current and projected climatic conditions. Details of the modelling of both agronomic and economic components are described in what follows.

\subsection{Agronomic Component}

The agronomic component of the model was used to simulate crop yields under four different scenarios: a current climate baseline scenario for the period 1993-2012 (Now); a climate change scenario for the period 2046-2065 (Climate Change); and, the previous scenarios with additional farming practices to reduce crop stress ( $\mathrm{Now}^{+}$, Climate Change ${ }^{+}$).

Climate conditions for the period 1993-2012 corresponded to weather observations for the climatological station of Ukkel, Belgium $\left(50^{\circ} 47^{\prime} 55^{\prime \prime} \mathrm{N}, 4^{\circ} 21^{\prime} 29^{\prime \prime} \mathrm{E}, 100 \mathrm{~m}\right.$ a.s.l.). Climate conditions for the period 2046-2065 were obtained from an ensemble of fifteen regional circulation models under emission scenario A1B ${ }^{5}$ (Semenov and Stratonovitch (2010) [47]) and corresponding $\mathrm{CO}_{2}$ concentrations ${ }^{6}$. The stochastic LARS Weather Generator ${ }^{7}$ (LARS-WG v5; Semenov (2008) [46]) was used to downscale the circulation model outputs for a suite of climate variables based on 1947-2012 observations for Ukkel (Zamani et al. (2015) [58]). The data included daily time series of maximum and minimum temperature $\left({ }^{\circ} \mathrm{C}\right)$, precipitation $(\mathrm{mm})$, potential evapotranspiration $\left(\mathrm{mm} \cdot \mathrm{day}^{-1}\right)$ and solar radiation $\left(\mathrm{MJ} . \mathrm{mm}^{-2} \cdot \mathrm{day}^{-1}\right)$. Figure 1 illustrates the $90^{\text {th }}$ percentile for rainfall versus the $90^{\text {th }}$ percentile for temperature for simulated climate series results. HIST refers to the historical climate scenario corresponding to the period 1947-2012 and the other labels refer to the 15

with risk, might increase the empirical potential of programming models of decision-making.

${ }^{5}$ We checked that the recently available but limited realisations of RCP scenarios for our study area are encompassed in the ensemble of projected meteorological time series used in this study.

${ }^{6}$ The $\mathrm{CO}_{2}$ concentrations that we used are similar to the RCP8.5 $\mathrm{CO}_{2}$ concentrations for the 2046-2065 period. The choice for an extreme scenario, similar to RCP85, is related to the time horizon for which agro-economic settings were assumed to be valid, and for which pronounced differences were present in the climatological datasets.

${ }^{7}$ The LARS-WG, which is known for the assessment of agricultural and hydrological risk, has been claimed to improve simulation of extreme weather events, such as extreme daily precipitation, long dry spells and heat waves. In addition, LARS-WG has been well validated in diverse climates around the world. 
different climate models corresponding to the period 2046-2065, as described previously.

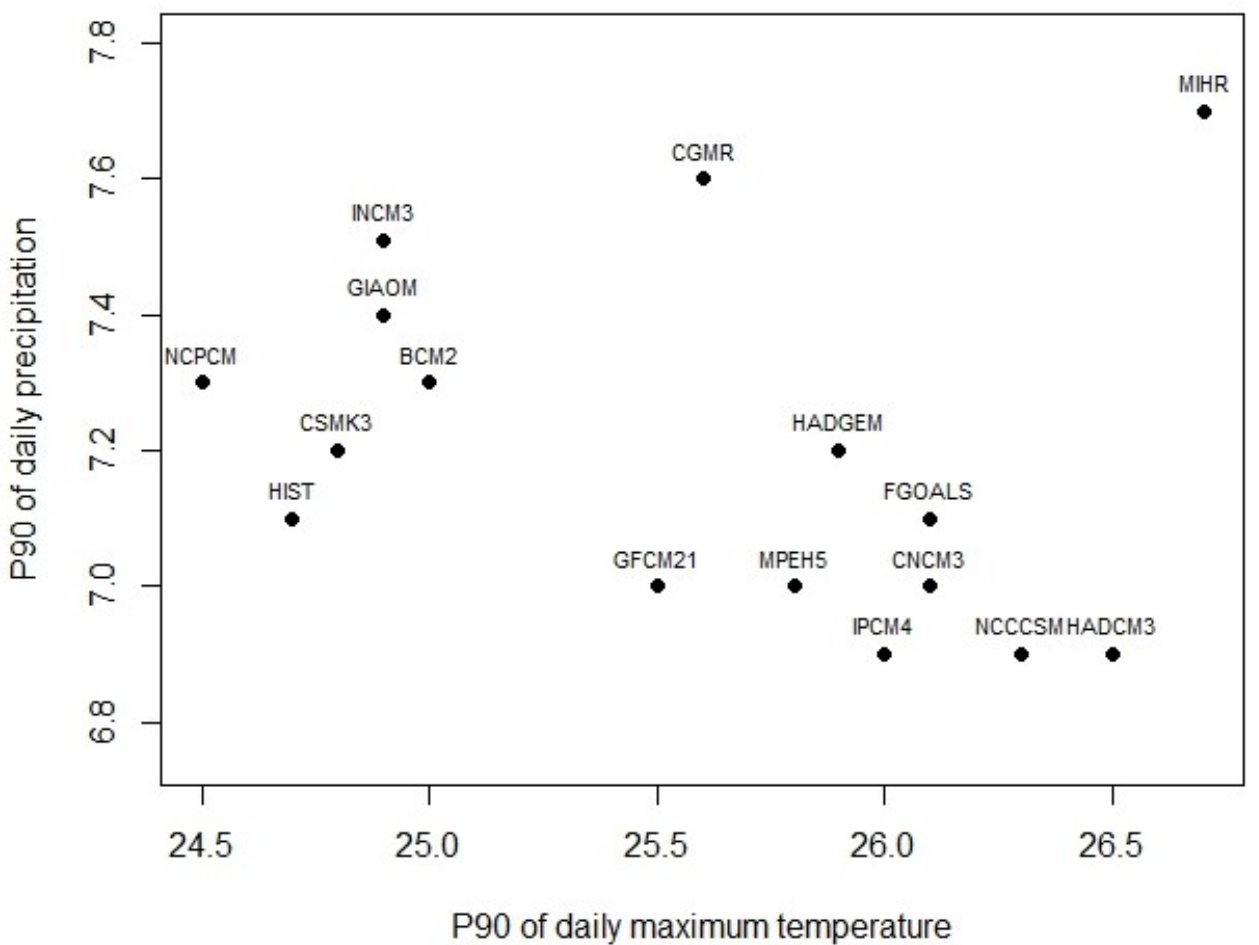

Figure 1: $90^{\text {th }}$ percentile of daily precipitation $\left(\mathrm{mm}\right.$ day $\left.{ }^{-1}\right)$ and daily maximum temperature $\left({ }^{\circ} \mathrm{C}\right)$. HIST refers to the historical period 1947-2012 and the other labels refer to 15 different climate models for the period 2046-2065. Zero values were incorporated in the precipitation series.

The current and projected climate series were ingested in the agronomic component of the model to obtain 20-year simulated mean yields and irrigation requirements for five arable crops (winter wheat, winter barley, potatoes, sugar beet, grain maize) on a loam soil in Central Belgium. The regional dynamic agri-meteorological model REGCROP, calibrated for regional arable yields (Gobin (2010) [13]), formed the core of the agronomic component. The model consisted of a coupled biomass and water balance model (Gobin 
(2010, 2012) [13], [14]) to simulate daily time series of crop growth conditions and yield. The water balance was a single-layer varying size bucket model and comprised an atmospheric compartment with daily rainfall, temperature and evapotranspiration (Allen et al. (1998) [2]) as input variables; a soil compartment based on soil-water physical properties and equations; and, a coupled soil moisture-biomass model which is optimised during subsequent model runs. In particular, the combined effects of climate variability, $\mathrm{CO}_{2}$ concentrations and related stress resulted in altered growth conditions due to carbon fertilization, drought and heat stress.

Model scenarios $\mathrm{Now}^{+}$and Climate Change ${ }^{+}$include the consideration of additional farming practices. Indeed, in the Loam Region of Belgium, current but not widespread farm practices of crop stress reduction include irrigation of potato and maize (Janssens (2015) [26]); and, crop residue management, which is known as a soil and water conservation technique (Parvin (2017) [39]). Therefore, we incorporated these farm practices in the scenarios to define $\mathrm{Now}^{+}$and Climate Change ${ }^{+}$. Crop stress was reduced through irrigation of late potato and grain maize in the baseline scenario $\left(\mathrm{Now}^{+}\right)$, and irrigation of all crops in the projected climate scenario (climate change $^{+}$). In addition, soil and water conservation

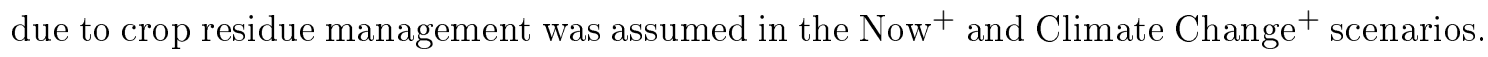
The residue management practices resulted in reduced soil evaporation and improved soil hydrological properties (Saxton and Rawls (2006) [44]) in favour of the soil water balance (Parvin (2017) [39]).

In summary, from the agronomic component of the model, we obtained 20-year series of simulated average yields and irrigation requirements for 5 arable crops and 4 different scenarios, which served as inputs to the economic model. Simulated yields and the water requirement results per scenario are shown and described in section 3.1.

\subsection{Economic Component}

The economic component of the model is based on a Positive Mathematical Programming (PMP) approach. Most mathematical programming models with a strong biophysical component, use what is called Normative mathematical programming (cf. Buysse et al. (2007) [6]). This type of models simulates, based on the assumed constraints, what the optimal 
choice of the farmer is. Defining all constraints is often a complicated task, and some of these constraints, such as crop rotation or equipment availability, have often not been considered as "hard" constraints that mainly drive the results. For this reason and in order to better reproduce observed choices, positive mathematical programming is developed and used to calibrate a behavioral function with respect to observed data and in this case, only the constraint of available land is considered as a "hard" constraint (cf. Buysse et al. (2007) [6] ). Although a variety of approaches exist, we have chosen to adapt the PMP model proposed by Cortignani and Severini (2012) [7] for a hypothetical farm, as this type of modelling approach allows to represent decision-making under uncertainty.

The main optimization problem consists of finding the vector of shares of land allocated to the different crops, $x$, that maximizes the expected utility of the farmer, $E(Z)$, defined as the sum for all crops of the crop specific expected gross margins minus fixed and variable costs minus a risk aversion farm-specific term, and constrained by the equation (2) of available land ${ }^{8}$. The problem of the farmer then becomes:

$$
\begin{gathered}
\max _{x} E(Z)=E(g)^{\top} x-d^{\top} x-\frac{1}{2} x^{\top} e x-c_{i}^{\top} x-\frac{1}{2} \phi x^{\top} \Sigma_{g} x \\
a^{\top} x \leq S \quad[\lambda]
\end{gathered}
$$

where $E(g)$ is the vector of expected unitary gross margin, $d$ and $e$ are the vector and the diagonal matrix of the quadratic cost function, $\phi$ is the farm specific absolute coefficient of risk aversion, $\Sigma_{g}$ is the covariance matrix of unitary gross margins, $c_{i}$ is the (per hectare) irrigation cost, $a$ is the unitary vector, $S$ corresponds to the total amount of land available and $\lambda$, the vector of the shadow price of the land ${ }^{9}$.

\footnotetext{
${ }^{8}$ We acknowledge that other constraints faced by the farmers, such as crop rotation or equipment availability, are not included in this PMP model, as explained previously. In addition, CAP payments are also not included in the objective function. In fact, while the most relevant CAP policies that affect crop decisions are meanwhile abolished, the currently applied decoupled income support is supposed to have no impact of crop allocation decisions.

${ }^{9}$ The shadow price of the land represents the rental price of the land and is uniform across the different crops. Thus, elements of vector $\lambda$ are equal.
} 
Let $\mathrm{K}$ be the set of crops and let $\mathrm{T}$ be the set of years, where $K=\{1 \ldots K\}$ and $T=\{1 \ldots T\}$. Input parameters of the previous optimization problem, $E(g)$ and $\Sigma_{g}$ are calculated using data from the study area and outputs of the agronomic model over a period of $T$ years. More specifically, $E\left(g_{k}\right)$ depends on price $\left(p_{k}\right)$ and yield $\left(y_{k}\right)$ of crop $k$, that are treated as dependent ${ }^{10}$ random vectors, which follow a discrete uniform distribution in the interval $[0, T]$, and $c_{k}^{s}$, the structural cost (per hectare), which mainly includes fixed $\operatorname{costs}^{11}$ for the crop $k$, such as lease and depreciation on machines. Thus,

$$
E\left(g_{k}\right)=E\left(p_{k}\right) * E\left(y_{k}\right)-c_{k}^{s} \quad \forall k \in K
$$

where

$$
\begin{aligned}
& E\left(p_{k}\right)=\frac{1}{T} \sum_{t} p_{k}^{t}, \\
& E\left(y_{k}\right)=\frac{1}{T} \sum_{t} y_{k}^{t} .
\end{aligned}
$$

The variance-covariance matrix $\Sigma_{g}$ is defined by the equations:

$$
\begin{gathered}
\Sigma_{g(k, k)}=\frac{1}{T-1} \sum_{t}\left(g_{k}^{t}-g_{k}\right)^{2}, \\
\Sigma_{g(k, l)}=\frac{1}{T-1} \sum_{t}\left(g_{k}^{t}-g_{k}\right)\left(g_{l}^{t}-g_{l}\right), \\
k, l \in K, \quad k \neq l,
\end{gathered}
$$

where $g_{k}^{t}=p_{k}^{t} y_{k}^{t}-c_{k}^{s}$ is the gross margin value from production of the $\mathrm{k}^{t h}$ crop at year $t$ and $g_{k}$ is the mean of the gross margins distribution.

Total irrigation costs (per hectare) per crop $\mathrm{k}, c_{i}(k)$, include fixed $c_{i f}$ and variable costs per crop $\mathrm{k}, c_{i v} I v(k)$, as described in equation (9),

\footnotetext{
${ }^{10}$ In particular, we assume that the price of crop $k$ in specific year $t, p_{k}^{t}$, relates to the corresponding year of simulated yield, $y_{k}^{t}$.

${ }^{11}$ These fixed costs are mainly made up of lease, depreciation on machines and fictitious interest, that is, "compensation" for the capital invested. They also include tool costs, such as the purchase of small materials, machinery and transport insurance, among others.
} 


$$
c_{i}(k)=c_{i f}+c_{i v} I v(k),
$$

where $c_{i f}$, the unit cost per ha, consists of pumping electricity and transportation costs (pipelines, fuel), $c_{i v}$, the unit cost per amount of water applied, represents additional electricity and/or fuel used, and $I v(k)$ corresponds to the water amounts required per crop. Parameters values $c_{i f}$ and $c_{i v}$ are derived from data for the study area and $I v(k)$ are outputs of the agronomic model (see details in section 3.3).

Finally, parameters $d, e, \phi$ and the vector of dual values, $\lambda$ were estimated with a maximum entropy program which is described in appendix $\mathrm{A}$.

\section{Data from the Loam region}

We applied the theoretical model to a hypothetical ${ }^{12}$ arable farm of 100 ha in the Loam region in the centre of Belgium (see Belgian agricultural regions in Figure 2).

The main part of the Loam region is situated in the region of Wallonia. The Quaternary loam layer is as deep as 20 metres in some parts of the region, constituting favourable conditions for annual arable crops (Ager (1989) [1]). The main arable crops include winter wheat, sugar beets, potatoes, winter barley and grain maize in decreasing order of planted area (cf. Van Herzele et al. (2013) [54] and [61]).

Belgium has a typically moderate Western European climate influenced by North Sea conditions, with slight differences in climate conditions across the country. The high variability of rainfall series makes it difficult to attribute the frequency and amplitude of rainfall extremes to global warming (Gobin (2012) [14]). However, monthly mean temperatures and the likelihood of heatwaves, have risen significantly over the past two decades. In particular, mean temperature has increased by around $1.2{ }^{\circ} \mathrm{C}$ and heatwaves have occurred 8 times more frequently in the last two decades (cf. [14]). Since the study area is mainly an agricultural region, changes on weather conditions due to climate change may have significant impacts on the agricultural activities and landscape, which makes the Loam region

\footnotetext{
${ }^{12}$ Even if arable farms are an average of 50 ha in the loam region, we choose a hypothetical farm of 100 ha in order to simplify the description and explanation of the results.
} 


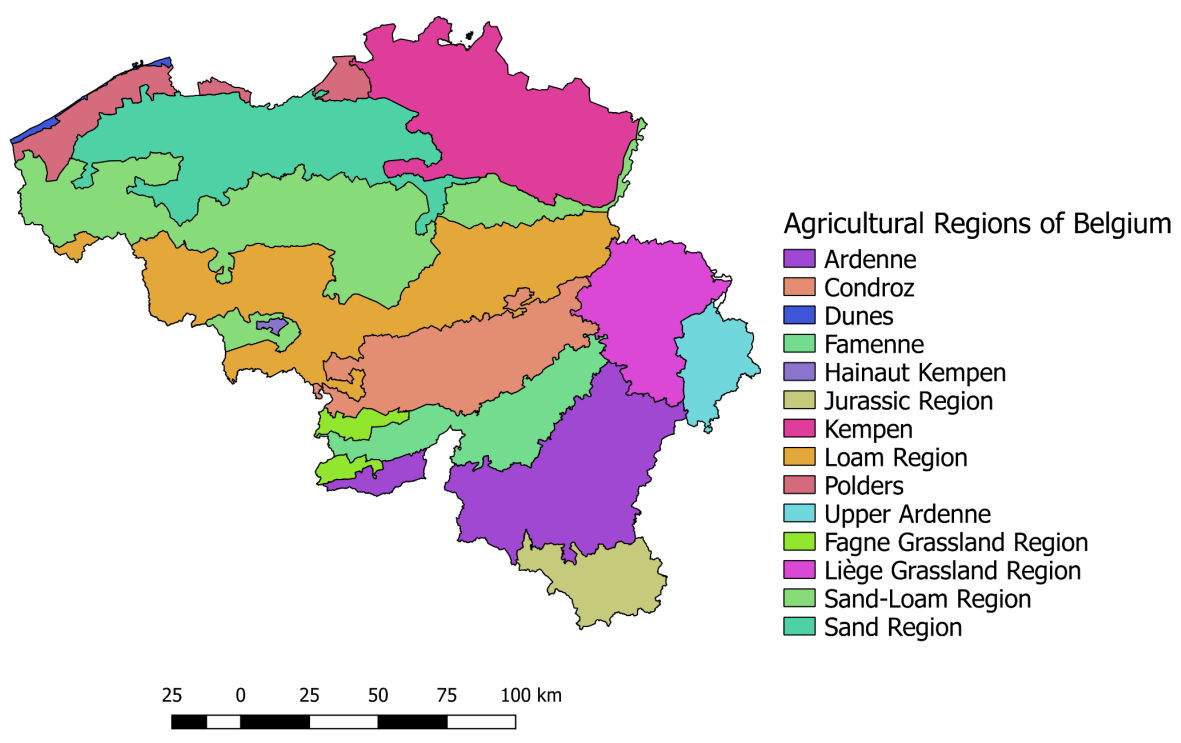

Figure 2: Agro-ecological regions in Belgium. Source Geographical data: Geopunt Vlaanderen [60]

an interesting case study for adaptation to climate change in Western Europe.

\subsection{Simulated agronomic data}

Yields and irrigation requirements simulated by the agronomic model, described in section 2.1, are summarized in Figure 3 and Tables 7 and 8 in Appendix B.2. First, in Figure 3, we observe on average, higher winter cereal yields (wheat and barley) and lower summer crop yields (late potatoes, sugar beet and grain maize) under climate change (scenarios Climate Change and Climate Change ${ }^{+}$) compared to the current scenario (scenarios Now and $\mathrm{Now}^{+}$), in the case and in the absence of applying additional farming practices to reduce crop stress, such as irrigation and soil and water conservation techniques ${ }^{13}$. In

\footnotetext{
${ }^{13}$ We note that scenarios with superscript + correspond to scenarios with additional farming practices measures to reduce crop stress.
} 
particular, as shown in Table 7, on average, higher impacts are observed in summer root crops such as Late Potatoes and Sugar Beet compared to cereals. This is due to the fact that extreme events such as drought and heat stress are more likely to happen in summer periods, and therefore their occurrence particularly affects summer crops. 


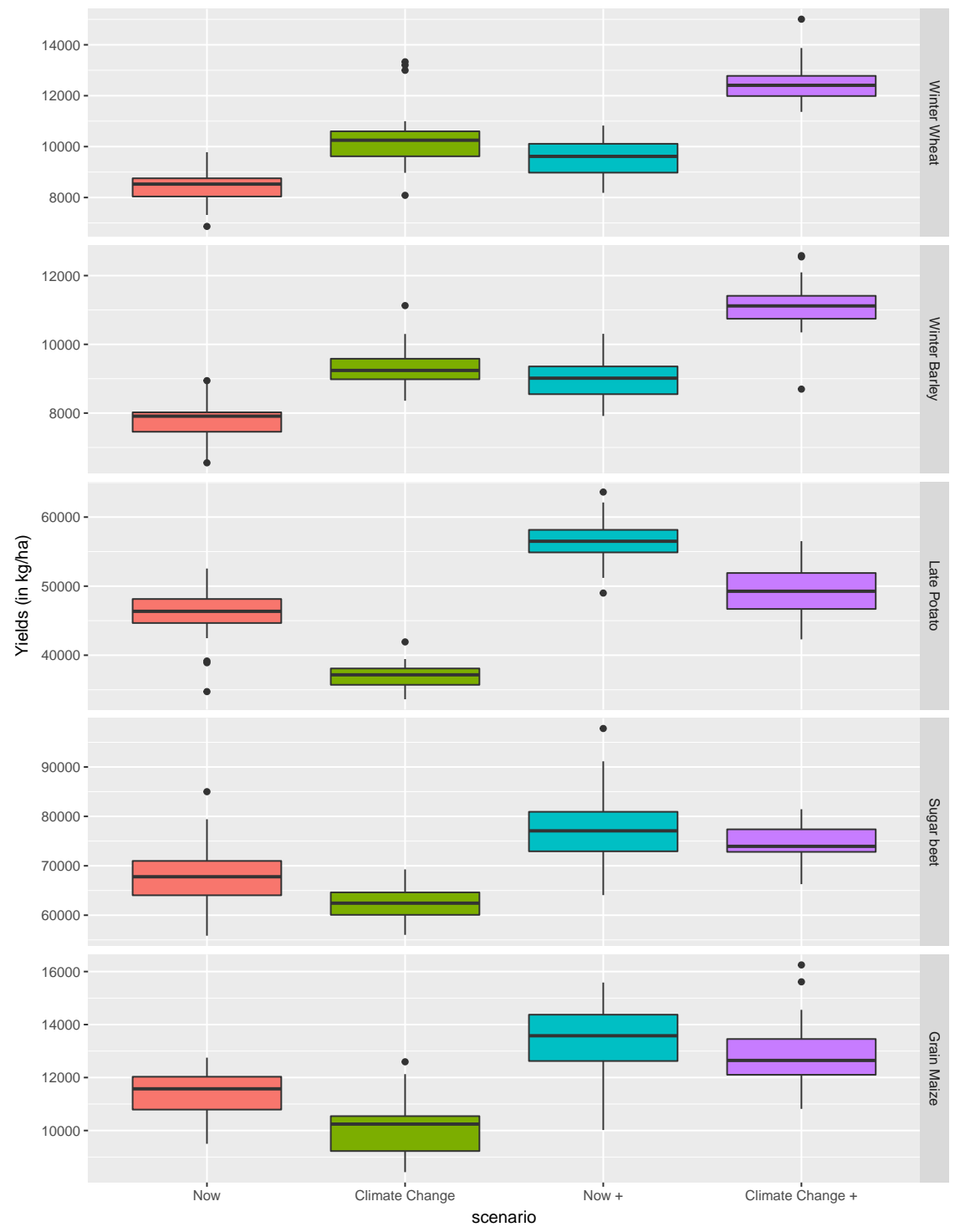

Figure 3: Boxplots of simulated yields (in $\mathrm{Kg} /$ ha fresh matter) for the different crops and scenarios: Current years, and Climate change, without (Now, and Climate Change) and with $\left(\mathrm{Now}^{+}\right.$, and Climate Change $\left.{ }^{+}\right)$irrigation measures and soil and water conservation techniques. Plots show the median, $25^{\text {th }}$ and $75^{\text {th }}$ percentiles in the box, with the $10^{\text {th }}$ and $90^{t h}$ percentiles in the whiskers and dots showing values beyond the $10^{\text {th }}$ and $90^{\text {th }}$ percentiles. 
In addition, when irrigation measures and soil and water conservation techniques are not applied, the variability in simulated yields, i.e. the difference between the 75 th percentile and the 25th percentile (represented in the Figure 3 by the box height) of cereals is higher under climate change as compared to the current scenario "Now", and lower in the case of late potatoes and sugar beet. Winter cereals benefit from drier periods during ripening, but suffer from wet periods and storms during ripening, which leads to a higher yield variability. Combined heat and drought stress explain the effects on summer root crop yields. However, differences in variability between scenarios are to be viewed in conjunction with magnitude.

When irrigation measures and soil and water conservation techniques are applied, i.e. in scenarios $\mathrm{Now}^{+}$and Climate Change ${ }^{+}$, we also obtain water applications per crop (see Table 8 in Appendix B.2). We observe two main results. On the one hand, higher water requirements are expected for all crops under climate change with respect to the current normal scenario. In particular, irrigation demand varies between $74-147 \mathrm{~mm}$ for late potatoes and $41-125 \mathrm{~mm}$ for grain maize under the current scenario ( $\mathrm{Now}^{+}$); and is significantly increased under climate change. The lowest irrigation requirements under climate change were calculated for winter barley $(24-105 \mathrm{~mm})$, followed by winter wheat (31-109 $\mathrm{mm})$; whereas the highest requirements were calculated for late potatoes (150-401 mm). On the other hand, additional measures have a significantly positive impact on average yields, and yield variability for most of the crops (see differences between $\mathrm{Now}^{+}$and Now or Climate Change ${ }^{+}$and Climate Change in the Figure). However, the application of additional measures did not enable summer crop yields under climate change (Climate Change $^{+}$) to increase to the level of current yields with additional measures $\left(\mathrm{Now}^{+}\right)$. In other words, additional measures do not alleviate all weather related stress in crops.

\subsection{Economic data}

Crop price values are described in Table 10 in Appendix B.4 and corresponded to the period 1993-2012 (cf. ADSEI index [61] and cf. [59] for sugar beet prices), corresponding to crop yields under the baseline scenario (Now). Due to the uncertainty surrounding future prices, in section 4.1, we firstly focus on the analysis of land-use management results for 
the different model scenarios, by assuming no change on prices under climate change. However, following climate change projections, prices are expected to be one of the more sensitive economic parameters affected by climate change. In section 4.2 , we simulated a change in crop prices under climate change scenarios in case of absence of additional farm practices (i.e. "Climate Change" scenario) and analyzed land-use adaptation under these assumptions. We considered different projections for crop prices consistent with existing literature (see Fernández and Blanco (2014) [10] for a review). These projected prices might be as high as $150 \%$ or as low as $-50 \%$ depending on the different IPCC scenarios. We then constructed different price scenarios, assuming changes in prices under climate change: (1) for all crops; (2) for cereals only; (3) for sugar beet and potatoes; (4) for all crops except potatoes; (5) for cereals except maize; and, (6) for sugar beet only. The latter scenarios (4) and (6), where we assumed no changes in potatoes prices, are particularly interesting in the case of Belgium. The demand for potatoes in Belgium is high and stable because of the processing industry.

Typical structural costs (per hectare) for each crop in the Loam region were taken from the Belgian official reports [11], [27], [28] and summarized in Table 1. From equations $(3),(6)$ and (7), we subsequently calculated the expected revenue $E(g)$ and the covariance matrix $\Sigma_{g}$ which were inputs to the economic model.

\begin{tabular}{c|c|c|c|c|c|} 
& Winter Wheat & Winter Barley & Late Potatoes & Sugar Beet & Grain Maize \\
& $c_{1}^{s}$ & $c_{2}^{s}$ & $c_{3}^{s}$ & $c_{4}^{s}$ & $c_{5}^{s}$ \\
\hline Values & 606 & 520 & 1267 & 798 & 583
\end{tabular}

Table 1: Structural cost parameters $c_{i}^{s}$ for each crop $i$ (in $€ /$ ha).

Irrigation costs were taken into account in the scenarios with irrigation practices $\left(\mathrm{Now}^{+}\right.$, Climate Change $^{+}$), as fixed and variable costs. Fixed costs included investments in materials and technology for irrigation and were estimated at an average of around $225 € /$ ha/year in Belgium (Janssens (2015) [26]). Variable costs were obtained by multiplying the quantities of water dedicated to each crop (Table 8), which were outputs of the agronomic model, and the price of water application, estimated at around $50 €$ per irrigation application of $25 \mathrm{~mm}$ per hectare (cf. [26]). 


\subsection{Estimated values of Operating Costs and absolute risk aversion co- efficient}

\begin{tabular}{c|c|c|c|c|c|c} 
Year & 2009 & 2010 & 2011 & 2012 & 2013 & 2014 \\
\hline Winter Wheat & 51.21 & 53.05 & 51.17 & 53.53 & 51.67 & 52.55 \\
Winter Barley & 11.24 & 8.93 & 8.72 & 9.12 & 9.24 & 8.8 \\
Late Potato & 14.3 & 15.94 & 15.66 & 13.91 & 15.06 & 16.64 \\
Sugar Beet & 19.34 & 18.18 & 19.36 & 18.91 & 18.4 & 18.14 \\
Grain Maize & 3.91 & 3.9 & 5.09 & 4.53 & 5.63 & 3.87
\end{tabular}

Table 2: Land-use observations (in percentage) per crop for the period 2009-2014 in the Loam region.

The output values of the calibration program (see Appendix A) provided some of the inputs of the objective function (see equation 1) of the main optimization model, as described in section 2.2. The parameters of the quadratic and risk terms, $d, e, \phi$ were estimated with the calibration program based on arable land-use observations in the Loam region (see Table 2, cf. [61]) for the period 2009-2014 ${ }^{14}$. As in Heckelei and Wolff (2003) [17], for the current case of one resource constraint, the elements of vector $\mathrm{d}$ were not identified and were therefore set to zero. Calibrated values are listed in Table 3. The table also contains a column with the implied price elasticities of supply, defined as $E\left(p_{k}\right) * E\left(y_{k}\right) /\left[\left(e_{k}+\phi \Sigma_{g_{k}}\right) * x_{k}\right]$ per crop $k$. Values of the elasticities show clearer the expected simulated response of the different crops for the baseline scenario (Now). Elasticities includes both a response of the marginal quadratic cost component (with vector parameter $e$ ) and the risk aversion component (with vector parameter $\phi * \Sigma_{g_{k}}$ ). Calculated elasticities ${ }^{15}$ show that the acreages (vector $\mathrm{x}$ ) of cereals, in particular the acreage of barley, would react stronger on price changes than sugar beet and potatoes. At first sight, it would

\footnotetext{
${ }^{14}$ We do not consider the same period corresponding to yield simulations because of the absence of available data before 2009. However, we added observations in 2013-2014 in order to capture two different crop rotations (3-years per rotation) in the modelling.

${ }^{15}$ The calculated elasticities do not take the land constraint limitation into account and are therefore larger than the real elasticities.
} 
make sense that more profitable crops (sugar beet and potatoes) have higher acreages than less profitable crops (cereals). However, elasticities reflect the calibration behavior of the model. In other words, in order to force the model to reproduce observed acreages, higher marginal cost function parameters (parameter e) and lower elasticities, are obtained for more profitable crops.

In addition, in order to verify the robustness of our economic results, we tested the sensitivity of the unknown parameters of the calibration program, i.e. the support intervals and support points, as well as the shadow price of the land, $\lambda$. Indeed, the shadow price of the land $\lambda$ has been fixed in the calibration program in order to avoid the criticized first step of traditional PMP models (cf. Heckelei and Wolff (2003) [17]) and has been set to $269 € /$ ha (i.e. the rental price of the land in the study area), as explained in appendix A. Thus, we have also performed a sensitivity analysis with respect to this parameter, assuming normal distribution $\mathcal{N}(269,102)$, with mean and standard deviation based on available statistical data from 2009-2013 in Belgium (cf. [61]). Results of the sensitivity analysis are summarized in section 4.3 .

\begin{tabular}{c|c|c||c} 
Crop & ME outputs (unit) & Output values & Supply elasticities \\
\hline Winter Wheat & $e_{1}(€ /$ ha.ha) & 0.98 & 2.76 \\
Winter Barley & $e_{2}(€ /$ ha.ha) & 0 & 12.95 \\
Late Potatoes & $e_{3}(€ /$ ha.ha) & 86.55 & 1.8 \\
Sugar Beet & $e_{4}(€ /$ ha.ha) & 77.58 & 1.72 \\
Grain Maize & $e_{5}(€ /$ ha.ha) & 102.19 & 2.94 \\
\hline & $\phi$ (unitless) & $1.010619 \mathrm{E}-5$ &
\end{tabular}

Table 3: Calibrated values/outputs of the maximum entropy (ME) model and corresponding supply elasticities. 


\section{Results for the Loam region}

\subsection{Land-use adaptation to climate change}

Results of simulated surfaces allocated to winter wheat, winter barley, sugar beet, late potatoes and grain maize for a hypothetical farm of 100 ha, obtained for the different modelling scenarios are presented in Table 4 . First of all, we analyze land-use adaptation to climate change without considering irrigation measures and soil and water conservation techniques, i.e. the comparison between scenarios Now (column 3) and Climate Change (column 4) in Table 4. Simulation results show that the land share for wheat increases by 24 hectares (ha), while the surface allocated to barley, sugar beet, potatoes and grain maize decreases by around 10, 6, 5 and 3 ha respectively. More specifically, winter barley is gradually phased out and grain maize covers a small acreage in projected simulations under climate change. These results are along the same lines as agronomic simulations for projected yields (cf. section 3.1) except in the case of winter barley where yields are expected to increase and the share of land to decline. This is related to the fact that, even if the calibrated value of the non-linear cost parameter associated with winter barley is the lowest among crops and equals approximately zero in this data setting, the "risk term" (which was defined in the last term of equation (1)) of winter barley (around 69 $€ /$ ha) is greater than that of winter wheat (around $61 € /$ ha), (see Table 9 in Appendix B.3 for risk term results per crop per scenario). Thus, concerning winter crops, farmers' preferences pointed towards retaining crops with the lowest risk, i.e. winter wheat. These tendencies concerning land-use adaptation are maintained if we assume crop cultivation with irrigation and soil and water conservation techniques in the current normal and climate change scenarios (i.e. $\mathrm{Now}^{+}$(column 5) and Climate Change ${ }^{+}$(column 6) scenarios in Table 4).

Next, in Figure 4, we can observe expected utility results with and without land-use adaptation for the different scenarios. More specifically, surfaces of the baseline case (scenario "Now" in Table 4) are considered in order to compute the expected utility without adaptation, while land-use results for the different scenarios, which are presented in Table 4, are considered in the case of land-use adaptation. Firstly, we show that land-use 


\begin{tabular}{c|c|c|c||c|c} 
& unit & \multicolumn{5}{|c}{ Scenarios } \\
& & Now & Climate Change & Now $^{+}$ & Climate Change $^{+}$ \\
\hline Winter Wheat & ha & 52.1 & 76.18 & 57.05 & 78.34 \\
Winter Barley & ha & 9.74 & 0 & 0.44 & 0 \\
Late Potatoes & ha & 15.14 & 8.95 & 17.58 & 8.39 \\
Sugar beet & ha & 18.63 & 13.94 & 21.88 & 13.28 \\
Grain Maize & ha & 4.39 & 0.93 & 3.04 & 0
\end{tabular}

Table 4: Surfaces allocated to the different crops for the different scenarios: current year without (Now) and with irrigation measures and soil and water conservation techniques $\left(\mathrm{Now}^{+}\right)$and climate change without (Climate Change) and with irrigation measures and soil and water conservation techniques (Climate Change ${ }^{+}$).

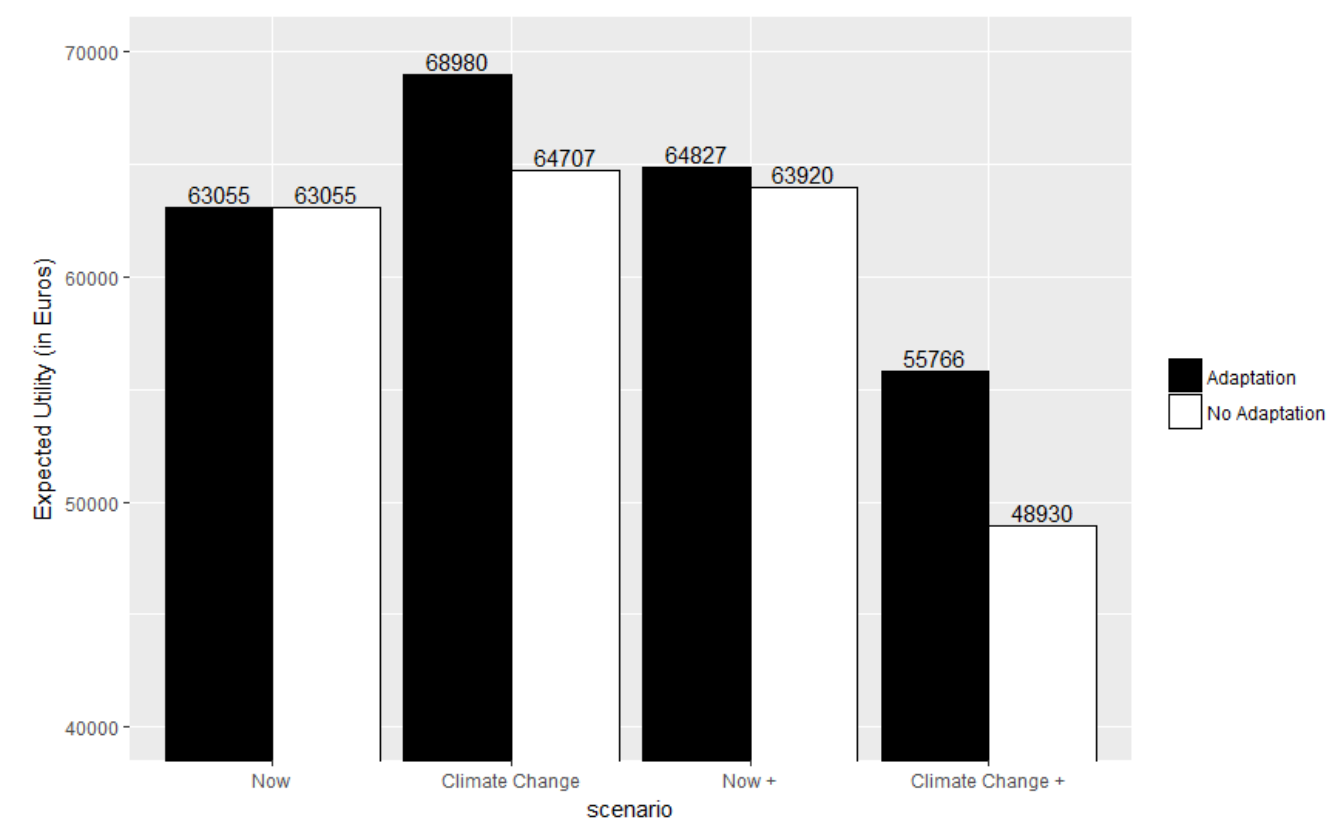

Figure 4: Expected utility for the different scenarios with and without land-use adaptation.

adaptation is always justified as expected utility increases for the different scenarios in the case of land-use adaptation with respect to the case without adaptation. In particular, expected utility increases by around 4273,907 and 6836 euros, which corresponds to 7 , 
1 and respectively $14 \%$, for the scenarios Climate Change, $\mathrm{Now}^{+}$and Climate Change ${ }^{+}$ respectively. Secondly, we show that climate change is positive for the farm economy when additional measures such as irrigation and water and soil conservation techniques are not applied, procuring a utility gain of 1652 (and 5925 euros) in the absence (respectively in the case) of land-use adaptation, (see differences between the scenarios Now and Climate Change without adaptation (respectively with adaptation)). Finally, additional measures procure a slight increase in utility under current climatic conditions (see scenarios Now and $\left.\mathrm{Now}^{+}\right)$. However, they are not justified under climate change, as expected utility drops by around 13-16 thousand euros, despite the application or the absence, of land-use adaptation measures (see scenarios Climate Change and Climate Change ${ }^{+}$). Indeed, simulated results show an increase in irrigation needs under climate change (see Table 8), which corresponds with expected water requirements in the existing literature (e.g. Janssens et al. (2014) [25]), leading to higher irrigation costs and important losses to farmers' individual utilities.

\subsection{Different price scenarios}

Figure 5 summarizes results of the price scenarios, which were simulated for the climate change scenario without additional practises (see a detailed description about the method used in section 3.2). Results for prices scenarios 'all crops' (scenario 1, top-left of the Figure) and 'Sugar beet and potatoes' (scenario 3, bottom-left of the Figure) show that summer (respectively winter) crops used a higher (respectively lower) share of land under the assumption of a general increase in crop prices under climate change scenarios. In particular, winter wheat is mainly substituted by sugar beet. The adaptation behaviour under higher crop prices subsequently leads to land-use results closer to the baseline case (scenario Now in blue dots). In the price scenarios (4) and (6), tendencies are similar, but potatoes are mainly replaced by winter wheat.

However, if we consider higher prices only for cereals and stable prices for sugar beet and potatoes (scenario (2)), preference was given to cereals, and summer crops gradually disappeared from the landscape. In scenario (5), where the maize price remains stable, results are similar in comparison to the previous scenario, but the area allocated to maize 

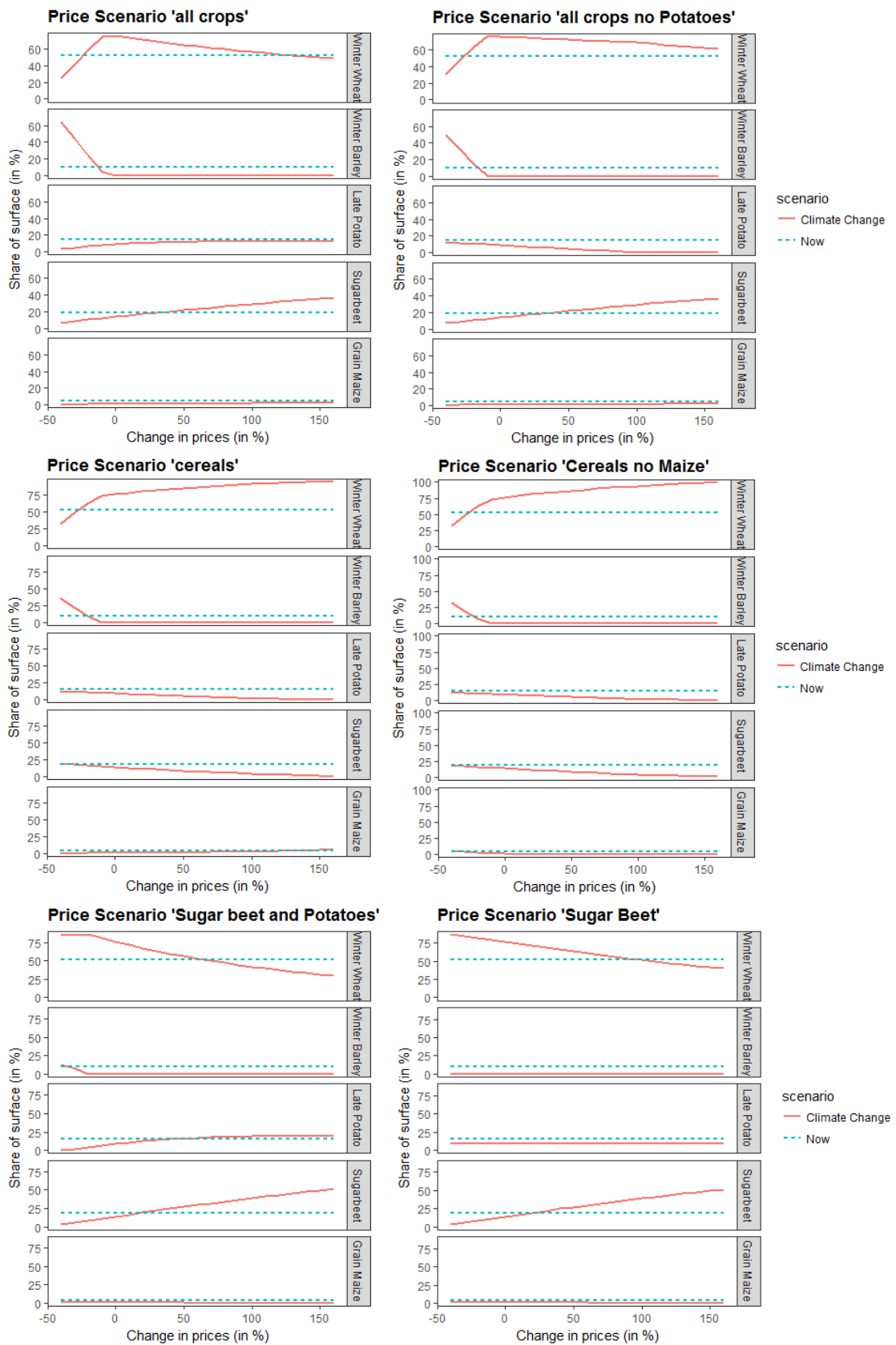

Figure 5: Changes in land-use for different prices scenarios under climate change. 
decreases slightly with an increase in prices for winter cereals.

Overall, adaptation behaviour under an expected increase in overall crop prices and summer crop prices (excluding cereals) leads to land-use results closer to the baseline case (scenario Now in blue dots). Logically, since we assumed that farmers behaved optimally, the expected individual utility increased with higher prices.

\subsection{Sensitivity analysis}

\begin{tabular}{|c|c|c|c|c|c|c|c|}
\hline \multirow[t]{2}{*}{$\begin{array}{c}\text { ME } \\
\text { outputs }\end{array}$} & \multirow[t]{2}{*}{ Baseline } & \multicolumn{2}{|c|}{$\lambda$} & \multicolumn{2}{|c|}{$\begin{array}{l}\text { Support interval } \\
\text { Lower: }[-10,50]\end{array}$} & \multicolumn{2}{|c|}{$\begin{array}{l}\text { Support Points } \\
\text { Lower: } 2 \text { pts. }\end{array}$} \\
\hline & & Mean & SD & Mean & SD & Mean & SD \\
\hline$e_{1}$ & 0.98 & 0.98 & 0.07 & 0.98 & $2.24 \mathrm{E}-04$ & 1.13 & 0.49 \\
\hline$e_{2}$ & 0 & 0 & 0 & 0 & 0 & 0.93 & 3.03 \\
\hline$e_{3}$ & 86.47 & 86.55 & 9.9 & 86.55 & $1.25 \mathrm{E}-03$ & 89.9 & 11.51 \\
\hline$e_{4}$ & 77.6 & 77.59 & 1.3 & 77.48 & 0.03 & 77.74 & 0.41 \\
\hline$e_{5}$ & 102.29 & 102.26 & 3.69 & 102.04 & 0.06 & 103.17 & 3.28 \\
\hline$\phi$ & $1.01 \mathrm{E}-05$ & $1.01 \mathrm{E}-05$ & $2.22 \mathrm{E}-06$ & $1.01 \mathrm{E}-05$ & $6.52 \mathrm{E}-10$ & $9.44 \mathrm{E}-06$ & $2.15 \mathrm{E}-07$ \\
\hline
\end{tabular}

Table 5: Sensitivity analysis with respect to unknown input parameters of the maximum entropy model.

Results of the sensitivity analysis performed with respect to unknown parameters values of the maximum entropy calibration program and the shadow price of the land (see specific method in section 3.3), are shown in Table 5. In particular, ME output values are shown for an stochastic shadow price, a more restrictive support interval and a lower number of support points. We conclude that the parameters estimated, quadratic costs for different crops and risk aversion, are robust with respect to the choice of $\lambda$, and the support interval. However, as expected, they are sensitive to a lower number of support points. Similar to the literature (cf. [17]), the higher the number of support points the greater reduction on estimated mean errors. This validates our initial choice of a high number of 5 support points. 


\section{Discussion}

Recent studies have argued that the projected changes in weather patterns due to climate change, and in particular the expected increase in mean temperature, could be beneficial for agricultural systems in Central and Northern Europe (Trnka et al. (2011) [51]). However, IPCC reports underline the uncertain consequences of other climate change impacts such as the increase in the frequency and magnitude of extreme weather events due to climate change. In particular, in Belgium, a progressive shift to southern European weather patterns, and a tendency towards more drought stress, and an increase in dry days are expected (cf. [51]), which could lead to important changes in expected positive impacts on crop yields (Reidsma et al. 2015 [42]). Even if the recent and extensive literature has focused on climate change impacts and adaptation at crop level, more research is still needed on adaptation at farm level to improve economic efficiency under climate change (Mandryk et al. 2017 [35]). Adaptation through farmers' practices as land-use choice, irrigation and soil and water conservation techniques are reported in regional (cf. Mandryk et al. 2017 [35]) and global studies (cf. Olesen et al. (2011) [37]) as the main measures to alleviate climate change impacts on crops.

We have subsequently developed an agro-economic model in which we analyze farmers' adaptation through land-use changes, to climate change in the Loam region (Belgium), as well as farmers' performance in economic terms. Results are analyzed with and without considering the application of additional measures such as irrigation and soil and water conservation techniques to reduce crop stress. Even if the study is performed at farm level, we consider that our agro-economic results have strong implications at regional scale, as crop acreages and yields represent those of the region.

First of all, we briefly discuss the results obtained on crop yield impacts described in detail in section 3.1, in order to understand the economic results. Our Agronomic results show modest positive impacts on average yields of winter cereals and strong negative impacts on average yields of summer crops, especially for sugar beet and potatoes, under climate change. In addition, under climate change, higher yield variability is projected for cereals than for summer root crops. Our results are mostly in line with the report 
published by the Belgian National Climate Commission in 2010 [18], studies undertaken in the Netherlands where climate conditions are similar (e.g. Schaap et al. (2013) [45]; Reidma et al. (2015) [42]), and European studies (e.g. Olesen et al. (2011) [37]; Trnka et al. (2011) [51]; Derying et al. (2014) [8]; Lesk et al (2016) [29]), although some differences are observed.

In [18], authors estimate that climate change impacts in Belgium would be limited and may even positive be for winter wheat production under the general assumption of an increase in mean temperature of not more than 3 degrees. Even if extreme weather events had unknown effects, summer drought is expected to negatively influence summer crops such as sugar beet and potatoes. In addition, heatwaves are expected to seriously affect sugar beet and potato production (cf. Van Oort et al. (2012) [55]; Reidma et al. (2015) [42]). In particular, though warming during spring and early summer may accelerate canopy development and increase sugar beet yield, premature plant development can result in exposure of vulnerable plant tissues to extreme weather conditions, particularly during the sensitive stage of foliation expansion (cf. Gobin (2017) [15]). Other more general studies undertaken in Europe (e.g. [37]; [51]) are less optimistic with their estimations of crop yield impacts but overall tendencies are maintained. Slightly negative impacts are expected for winter wheat and with higher variability than for other cereals. For barley, drought is perceived as a more prominent risk in comparison to winter wheat. These results are in line with our agronomic results.

As regards grain maize, results differ between national and global studies. In Belgian studies, such as [18], authors argue that increased temperatures, coupled with the elevation of $\mathrm{CO}_{2}$ concentration, will be favourable for crop production. Moreover, $\mathrm{C} 4$ crops species are expected to perform relatively better under drought and heat stress conditions as compared to annual C3 cereal crops (Olesen et al. (2011) [37]). However, different results are obtained in our study. These are in line with Lesk et al. (2016), Derying et al. (2014) and Thornton et al. (2014), where heat stress is expected to negatively influence maize yields at global level. Differences with [18] are due to the fact that on the one hand, we have assumed that we are using similar varieties now and in the future under climate change, and on the other hand, we expect the occurrence of extreme events against which 
we propose a set of measures that will help reduce some impacts, notably those related to water shortages. Particularly, heat stress during flowering, low radiation during grain filling and excess rainfall are serious risks for maize production. These events do not always offset the benefits of $\mathrm{C} 4$ plants. Crop-stress measures will primarily take effect on the water balance, but do not always alleviate the impacts of other events.

Concerning economic results, land-use simulation results show an increase in areas of winter wheat and a decrease in summer crops and winter barley. This progressive shift to more winter wheat in systems dominated by root crops has been also obtained by Mandryk et al. (2017) [35] in an agricultural region in the Netherlands with similar climate conditions. Thus, changes in land-use follow the same patterns as the agronomic results, except for winter barley. Winter barley appears more vulnerable to climate related stress, in particular to drought and heat stress, than winter wheat, and therefore a progressive decrease in barley areas is observed in case of climate change. Results from some recent studies undertaken in Eastern Europe (e.g. Trnka et al. (2012) [52]; Iljkic et al. (2014) [20]) observe similar tendencies for barley.

Moreover, the uncertainty regarding future crop prices under climate change could affect our results. Indeed, the expected decrease in crop yields, due to a likely increase in drought risk, could be compensated for by an increase in prices in the near future. We show that an overall increase in crop prices, or an increase in summer crop prices, particularly for sugar beet and potatoes, will lead to simulated land-uses which will be close to the current situation.

Finally, previous Belgian studies (e.g. [18]) estimate moderate, or even zero, financial losses when adaptation is applied. Our results are more optimistic in the sense that positive gains are obtained when we assume land-use adaptation measures in the Loam region. In particular, expected utility increases by around $7 \%$ under climate change in the case of land-use adaptation with respect to the case without adaptation, and by around $9 \%$ with respect to the current situation. In addition, we also show that irrigation measures are not justified under climate change in the Loam region as they lead to important economic losses for the individual farmer that could reach $24 \%$ when land-use adaptation measures are not applied. However, if irrigation measures are ultimately necessary in the future, which 
was the case for projected climate impacts, land-use adaptation provides a utility gain of around $14 \%$ with respect to the case without adaptation. Similar results are obtained in Mandryk et al. (2017) [35] for a region with similar climate conditions and assuming a high impact emission scenario under climate change. In particular, a maximum $15 \%$ increase in gross margins compared to the current situation can be achieved when crop and farm level adaptations are applied in Flevoland (Netherlands).

However our study has some limitations. First of all, indirect effects of extreme weather events such as flooding and soil loss caused by runoff, could also be implemented in the agronomic model. Related to the economic approach, we could improve the performance of the calibration program by adding more calibration years or by using a stochastic dynamic approach with different crop rotations under climate change. Overall, other types of adaptation strategy could be analysed, such as new technology adoption and the use of new crop species that are more resilient to drought and heat stress. Finally, other empirical approaches such as, for example, Montecarlo simulations, could be performed in order to take into account the uncertainty of crop prices under climate change, as well as considering increases in water prices due to water scarcity, and uncertainty about other future costs of the farmers (e.g. future structural and operating costs).

\section{Conclusions}

We analyzed farm-level adaptation through land-use changes to climate change, for the specific case of the Loam region, in Belgium. For this purpose, we used an interdisciplinary model with agronomic and economic components. The main contribution of the paper is the economic assessment of climate change impacts in land-use choices in the Loam region, in Belgium. We showed that land-use adaptation to climate change consisted of an increase in the share of land allocated to wheat and a reduction in the share of land allocated to barley, sugar beet, potatoes and grain maize, with and without applying irrigation and soil and water conservation techniques. We concluded that adaptation to climate change through land-use changes had positive impacts on the farmer's individual utility, leading to a gain of around $9 \%$ with respect to the baseline scenario. Nevertheless, irrigation was 
not justified in the Loam region under climate change because of the high irrigation costs in Belgium. Moreover, by simulating a likely increase in crop prices under climate change, simulated land-use choices approximated to the farmers' current behaviour and the highest revenues should be expected in the case of land-use adaptation.

\section{Acknowledgements}

This work has been funded by the Belgian Science Policy Office (Belspo) under the "Meteorological risks as drivers of environmental innovation in agro-ecosystem management" (Merinova) project, with reference $\mathrm{SD} / \mathrm{RI} / 03 \mathrm{~A}$. 


\section{References}

[1] Ager, B., 1989. Chapter 7: Science Aura III: Findings Figured of 'Reading Science: A literary, Political and Sociological Analysis', General Hall Inc.: 108-153.

[2] Allen, R.G., Pereira, L.S., Raes, D., Smith, M., 1998. Crop evapotranspiration: guidelines for computing crop requirements. Irrigation and Drainage Paper 56, FAO, Rome.

[3] Antle, J.M., Stöckle, C.O., 2017. Climate impacts on agriculture: insights from agronomic-economic analysis. Review of Environmental Economics and Policy 11(2): 299-318.

[4] Berrang-Ford, L., Ford, J.D., Paterson, J., 2011. Are we adapting to climate change? Global Environmental Change 21: 25-33.

[5] Bradshaw, B., Dolan, H., Smit, B., 2004. Farm-level adaptation to climatic variability and change: crop diversification in the canadian prairies. Climatic Change 67: 119141.

[6] Buysse, J., Van Huylenbroeck, G., Lauwers, L., 2007. Normative, positive and econometric mathematical programming as tools for incorporation of multifunctionality in agricultural policy modelling. Agriculture, Ecosystems and Environment 120: 70-81. doi:10.1016/j.agee.2006.03.035

[7] Cortignani, R., Severini, S., 2012. Modeling farmer participation to a revenue insurance scheme by means of Positive Mathematical Programming. Agricultural Economics, 58 (7): 324-331.

[8] Deryng, D., Conway, D., Ramankutty, N., Price, J., Warren, R., 2014. Global crop yield response to extreme heat stress under multiple climate change futures. Environmental Research Letters 9, 034011 (13pp).

[9] Falloon, P., Betts, R., 2010. Climate impacts on European agriculture and water management in the context of adaptation and mitigation -the importance of an integrated approach. Science of the total environment 408(23): 5667-5687. 
[10] Fernández, F., Blanco, M., 2014. Integration of biophysical and agro-economic models to assess the economic effects of climate change on agriculture: A review of global and EU regional approaches, Economics Discussion Papers, No. 2014-48.

[11] Finger, R., Hediger, W., Schmid, S., 2011. Irrigation as adaptation strategy to climate change - a biophysical and economic appraisal for Swiss maize production. Climatic Change 105: 509-528.

[12] Foudi, S., Erdlenbruch, K., 2012. The Role of Irrigation in Farmers' Risk Management Strategies in France. European Review of Agricultural Economics 39 (3): 439-57.

[13] Gobin, A., 2010. Modelling climate impacts on arable yields in Belgium. Climate Research 44: 55-68.

[14] Gobin, A., 2012. Impact of heat and drought stress on arable crop production in Belgium. Natural Hazards and Earth System Sciences 12, 1911-1922.

[15] Gobin, A., 2017. Weather related risks in Belgian arable agriculture. Agricultural Systems 159: 225-236. https://doi.org/10.1016/j.agsy.2017.06.009

[16] Harrison, M. T., Cullen, B. R., Rawnsley, R. P., 2016. Modelling the sensitivity of agricultural systems to climate change and extreme climatic events. Agricultural systems 148: 135-148.

[17] Heckelei, T, Wolff. H., 2003. Estimation of constrained optimization models for agricultural supply analysis based on generalized maximum entropy. European Review of agricultural economics 30: 27-50.

[18] Hoyaux, J., Verheyden, S., Bogaert, J., Ghelen, Y., van Leest, M., Van der Avort, A., Squilbin, M., 2010. Belgian National Climate Change Adaptation Strategy. Edited by the National Climate Commission.

[19] Iglesias, A, Garrote, L., 2015. Adaptation strategies for agricultural water management under climate change in Europe. Agricultural water management 155: 113-124. 
[20] Iljkic, D., Kovacevic, V., Varga, I., 2014. Conference paper, $49^{\text {th }}$ Croatian \& $9^{\text {th }}$ International Symposium on Agriculture, Dubrovnik (Croatia).

[21] IPCC, 2007. Climate Change 2007: Fourth Assessment report of the Intergovernmental Panel on Climate Change. IPCC, Cambridge, United Kingdom/New York, NY, USA.

[22] IPCC, 2008. Technical Paper.

[23] IPCC, 2014. Climate Change 2014: Impacts, Adaptation, and Vulnerability. IPCC, Cambridge, United Kingdom/New York, NY, USA.

[24] Jahangir Kabir, Md., Alauddin, M., Crimp, S., 2017. Farm-level adaptation to climate change in western Bangladesh. Land Use Policy 64: 212-224.

[25] Janssens, P., Elsen, F., Odeurs, W., Coussement, T., Bries, J., Vandendriessche, H., 2014. Irrigation need and expected future water availability for potato production in Belgium. Oral presentation at the 19th Triennial Conference of the European Association for Potato Research, Brussels, July 6-11, 2014.

[26] Janssens, P., 2015. Grotere oogst na irrigeren. Management \& Techniek, 16 oktober 2015, pp. 18-19.

[27] Jourquin, S., 2012. Rentabiliteits- en kostprijsanalyse granen voor de korrel, Report.

[28] Jourquin, S., 2013. Rentabiliteits- en kostprijsanalyse van de suikerbietenteelt, Report.

[29] Lesk, C., Rowhani, P., Ramankutty, N., 2016. Influence of extreme weather disasters on global crop production. Nature 529 (7584), 84-87.

[30] Kaiser H. M., Riha S. J., Wilks D. S., Rossiter D. G., Sampath R., 1993. A FarmLevel Analysis of Economic and Agronomic Impacts of Gradual Climate Warming. American Journal of Agricultural Economics 75(2): 387-398.

[31] Klein, T., Holzkämper, A., Calanca, P., Seppelt, R., Fuhrer, J., 2013. Adapting agricultural land management to climate change: a regional multi-objective optimization approach. Landscape Ecology 28(10): 2029-2047. 
[32] Liu, B., Asseng, S., Liu, L., Tang, L., Cao, W., Zhu Y., 2016. Testing the responses of four wheat crop models to heat stress at anthesis and grain filling. Global Change Biology 22(5): 1890-1903.

[33] Liu, X., Lehtonen, H., Purola, T., Pavlova, Y., Rotter, R., Palosuo, T., 2016. Dynamic economic modelling of crop rotations with farm management practices under future pest pressure. Agricultural Systems 144: 65-76.

[34] Mandryk, M., Reidsma, P., Kanellopoulos, A., Groot, J.J., Ittersum, M., 2014. The role of farmers' objectives in current farm practices and adaptation preferences: a case study in Flevoland, the Netherlands (regional environmental change). Reg. Environ. Chang. 14 (4):1463-1478. http://dx.doi.org/10.1007/s10113-014-0589-9.

[35] Mandryk, M., Reidsma, P., van Ittersum, M.K., 2017. Crop and farm level adaptation under future climate challenges: an exploratory study considering multiple objectives for Flevoland, the Netherlands. Agricultural Systems 152: 154-164.

[36] Mu, J. E., McCarl, B. A., Wein, A. M., 2013. Adaptation to climate change: changes in farmland use and stocking rate in the U.S. Mitigation and Adaptation Strategies for Global Change 18: 713-730.

[37] Olesen, J.E., Trnka, M., Kersebaum, K.C., Skjelvåg, A.O., Seguin, B., PeltonenSainio, P., Rossi, F., Kozyra, J., Micale, F., 2011. Impacts and adaptation of European crop production systems to climate change. European Journal of Agronomy 34, 96-112.

[38] Paris, Q., Arfini, F., 2000. Frontier Cost Functions, Self selections, Price risks, PMP and Agenda 2000. Working Paper Series.

[39] Parvin, N., 2017. Effect of different crop residue management on soil hydraulic properties-a study in a silt loam soil in Belgium, Doctoral dissertation, University of Liège, Liège, Belgium.

[40] Petsakos, A., Rozakis, S., 2015. Calibration of agricultural risk programming models. European Journal of Operational Research 242: 536-545. 
[41] Powell, J.P., Reinhard, S., 2016. Measuring the effects of extreme weather events on yields. Weather and Climate Extremes 12: 69-79.

[42] Reidsma, P., Wolf, J., Kanellopoulos, A., Schaap, B.F., Mandryk, M., Verhagen, J., van Ittersum, M.K., 2015. Climate change impact and adaptation research requires integrated assessment and farming systems analysis: a case study in the Netherlands. Environmental Research Letters 10 (4).

[43] Roco, L., Engler, A., Bravo-Ureta, B., Jara-Rojas, R., 2014. Farm level adaptation decisions to face climatic change and variability: Evidence from Central Chile. Environmental Science \& Policy 44: 86-96.

[44] Saxton, K.E., Rawls, W.J., 2006. Soil water characteristic estimates by texture and organic matter for hydrologic solutions. Soil science society of America Journal 70(5): 1569-1578.

[45] Schaap, B.F., Reidsma P., Verhagen, J., Wolf, J., van Ittersum, M.K., 2013. Participatory design of farm level adaptation to climate risks in an arable region in the Netherlands. European Journal of Agronomy 48: 30-42.

[46] Semenov, M.A., 2008. Simulation of extreme weather events by a stochastic weather generator. Climate research 35: 203-212.

[47] Semenov, M.A., Stratonovitch, P., 2010. The use of multi-model ensembles from global climate models for impact assessments of climate change. Climate Research 41: 1-14.

[48] Seo, S. N., Mendelsohn, R., 2008. An analysis of crop choice: adapting to climate change in South American farms. Ecological economics 67: 109-116.

[49] Smit, B., Skinner, M., 2002. Adaptation options in agriculture to climate change: a typology. Mitigation and adaptation strategies for global change 7: 85-114.

[50] Thornton, P.K., Ericksen, P.J., Herrero, M., Challinor, A.J., 2014. Climate variability and vulnerability to climate change: a review. Global change biology 20: 3313-3328. 
[51] Trnka, M., Olesen, J.E., Kersebaums, K.C., Skjelvåg, A.O., Eitzinger, J., Seguin, B., Peltonen-Sainio, P., Rötter, R., Iglesias, A., Orlandini S., Dubrovský, M., Hlavinka, P., Balek, J., Eckersten, H., Cloppet, E., Calanca, P., Gobin, A., Vučetić V., Nejedlik, P., Kumar, S., Lalic, B., Mestre, A., Rossi, F., Kozyra, J., Alexandrov, V., Semerádová, D., Žalud, Z., 2011. Agroclimatic conditions in Europe under Climate Change, Global Change Biology 17: 2298-2318.

[52] Trnka, M., Brázdil, R., Olesen, J.E., Eitzinger, J., Zahraníček, P., Kocmánková, E., Dovrovolný, P., Štěpánek, P., Možný, M., Bartošová, L., Hlavinka, P., Semerádová, D., Valášek, H., Havlíček, M., Horáková, V., Fisher, M., Žalud, Z., 2012. Could the changes in regional crop yields be a pointer of climatic change? Agricultural and Forest Meteorology 166-167: 62-71.

[53] Trnka, M., Rötter, R.P., Ruiz-Ramos, M., Kersebaum, K.C., Olesen, J.E., Žalud, Z. and Semenov, M.A., 2014. Adverse weather conditions for European wheat production will become more frequent with climate change. Nature Climate Change 4(7): 637-643.

[54] Van Herzele, A., Gobin, A., Van Gossum, P., Acosta-Michlik, L., Waas, T., Dendoncker, N., Henry de Frahan, B., 2013. Effort for money? Farmers' rationale for participation in agri-environment measures with different implementation complexity. Journal of Environmental Management 131: 110-120.

[55] Van Oort, P.A.J., Timmermans B.G.H., Meinke, H., Van Ittersum, M.K., 2012. Key weather extremes affecting potato production in The Netherlands. European Journal of Agronomy 37: 11-22.

[56] WMO, 2011. Weather Extremes in a Changing Climate: Hindsight on Foresight. ISBN: 978-92-63-11075-6. Geneva, Switzerland.

[57] White, J.W., Hoogenboom, G., Kimball, B.A., Wall, G.W., 2011. Methodologies for simulating impacts of climate change on crop production. Field Crop Research 124, $357-368$. 
[58] Zamani, S., Gobin, A., Van de Vyver, H., Gerlo, J., 2015. Atmospheric drought in Belgium - Statistical analysis of precipitation deficit. International Journal of Climatology 36(8): 3056-3071.

[59] Confédération des Betteraviers Belges website, available at http://www.cbb.be/fr/betteraves-en-belgique

[60] Geopunt Vlaanderen website, available at http://www.geopunt.be/catalogus/datasetfolder/3cd62a4d-cef5-453e-b7c8$7 \mathrm{c} 786 \mathrm{afa} 7 \mathrm{f} 4 \mathrm{f}$

[61] Statitics Belgium website, available at http://statbel.fgov.be/nl/statistieken/cijfers/ 


\section{A The maximum entropy program: Model and assumptions}

We use a maximum entropy program which was introduced by Heckelei and Wolff. $\mathrm{H}$ (2003) [17] and adapted by Cortignani and Severini (2012) [7] with the aim of considering risk aversion. $\mathrm{K}, \mathrm{Q}$ and $\mathrm{N}$ are the sets of the model, where $\mathrm{K}$ is the number of crops, $\mathrm{Q}$ is the number of support points and $\mathrm{N}$ is the number of observation years.

The objective of the program is to find the vectors of probabilities $w_{k q}^{n}$, the parameters of the quadratic costs, $d_{k}, e_{k}$, the absolute risk aversion coefficient, $\phi$, and the shadow price, $\lambda$ that maximize the entropy level, $H$, described in equation (10), subject to first order conditions of the problem described in section 2.2 (equation (11)) which are evaluated in observations years, to error terms (12), land (13) constraints and the vector of probability condition (14). Error terms (12) are reparameterised as expected values of a discrete probability distribution and can be represented as the multiplication of $z_{q}$, the support values with the vector of probabilities $w_{k q}^{n}$.

In order to obtain a stable optimal solution, we assume $Q=5$ support points in the support interval $[-1000,5000]^{16}$ for each error term $\epsilon_{k}$. As stated in [17], the "right" number of support points, as well as the range of support is often discussed but not ultimately resolved. In particular, three or four support points and a support range with the "3-sigma" rule are commonly accepted as they promise a limited reduction in the mean estimation error. Finally, the shadow price, $\lambda$, is also fixed in order to reduce the complexity of the optimization model. We assume then that $\lambda$ is equal to the land rental price in the study area in 2013, which represents the last year simulated by the agro-economic model. $\lambda$ is then equal to $269 € /$ ha (cf. [61]). In order to verify the robustness of our assumptions, we have performed a sensitivity analysis of the support intervals, support points and the shadow price, the results of which are shown in section 4.3.

$$
\max _{w_{k q}^{n}, d_{k}, e_{k}, \phi, \lambda} H=-\sum_{n, k, q} w_{k q}^{n} \ln w_{k q}^{n}
$$

\footnotetext{
${ }^{16}$ Simulations were also performed with the symmetric support interval [-5000,5000] and results were not significantly different with respect to the asymmetric interval [-1000, 5000].
} 
s.t.

$$
\begin{gathered}
E\left(g_{k}\right)-d_{k}-e_{k}\left(x_{k}^{n}-\epsilon_{k}^{n}\right)-c_{i, k}-\Sigma_{g_{k}} \phi\left(x_{k}^{n}-\epsilon_{k}^{n}\right)-\lambda^{n}=0 \\
\epsilon_{k}=\sum_{q} z_{q} w_{k q}^{n} \\
\sum_{k} x_{k}^{n}-\epsilon_{k}^{n}=S \\
\sum_{q} w_{k q}^{n}=1
\end{gathered}
$$

$\forall k \in K, \quad \forall q \in Q, \quad \forall n \in N$

B The main optimization model: additional information and data.

B.1 Input/output summary data 


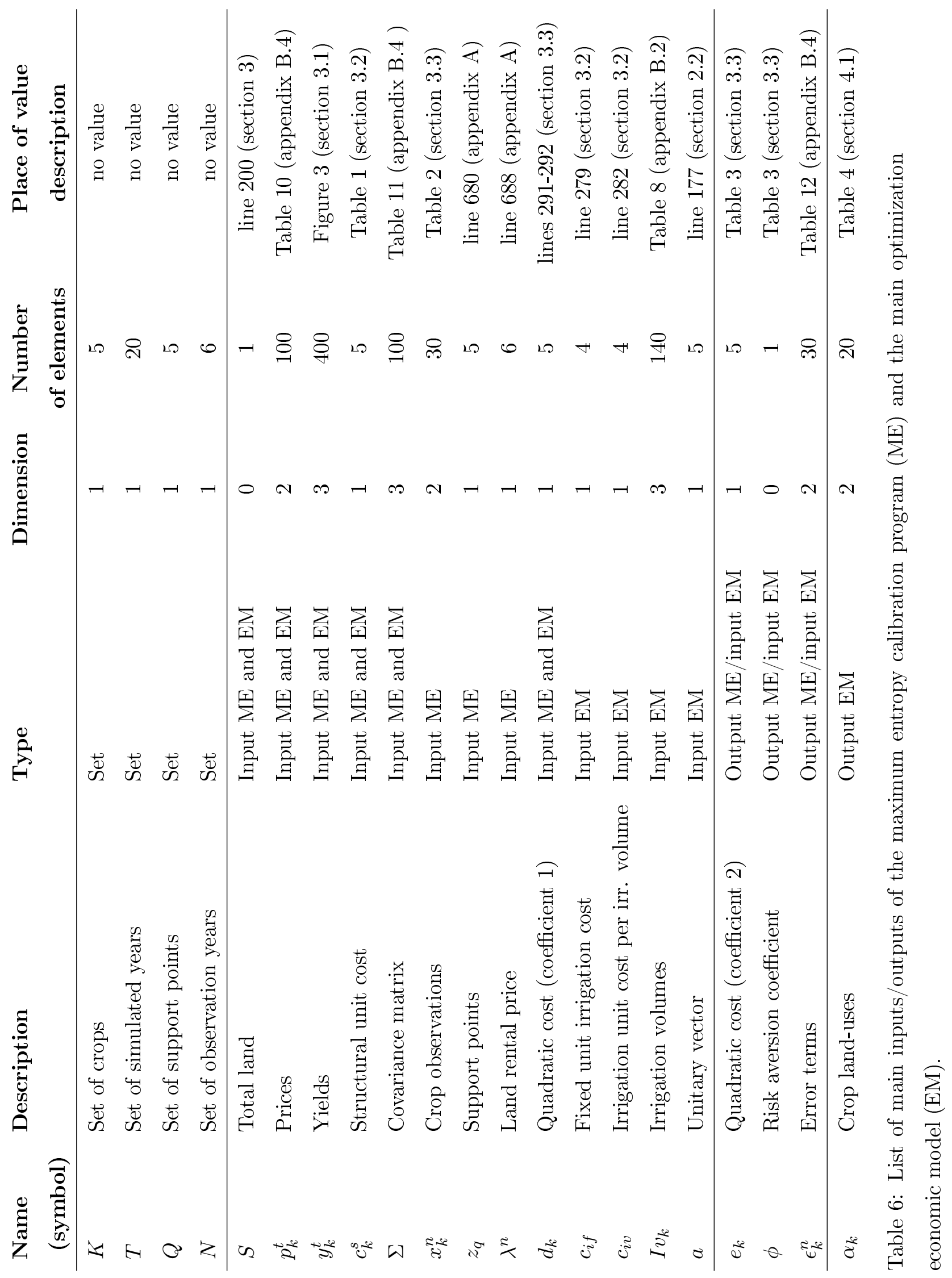


B.2 Outputs of the agronomic model: simulated yields and water requirements

\begin{tabular}{c|c|c|c|c|} 
& \multicolumn{2}{|c|}{ Without additional measures } & \multicolumn{2}{c|}{ With additional measures $(+)$} \\
Wean & Q3-Q1 & Mean & Q3-Q1 \\
Winter Wheat & 2024 & 266 & 2970 & -341 \\
Winter Barley & 1565 & 33 & 2126 & -140 \\
Late Potatoes & -8780 & -1105 & -7245 & 1942 \\
Sugar Beet & -5191 & -2401 & -3246 & -3439 \\
Grain Maize & -1306 & 78 & -417 & -399
\end{tabular}

Table 7: Mean and Variability (Q3-Q1) of differences between projected yields under climate change and simulated current normal years, with and without irrigation measures and soil and water conservation techniques (i.e. scenarios with and without superscript symbol +). 


\begin{tabular}{|c|c|c|c|c|c|c|c|c|c|c|}
\hline \multirow[b]{2}{*}{ Year } & \multicolumn{5}{|c|}{ Now $^{+}$} & \multicolumn{5}{|c|}{ Climate Change $^{+}$} \\
\hline & WW & WB & LP & SB & GM & WW & WB & LP & SB & GM \\
\hline 1 & 0 & 0 & 104 & 0 & 94 & 40 & 43 & 265 & 202 & 165 \\
\hline 2 & 0 & 0 & 147 & 0 & 41 & 84 & 47 & 161 & 292 & 153 \\
\hline 3 & 0 & 0 & 114 & 0 & 91 & 64 & 69 & 254 & 237 & 271 \\
\hline 4 & 0 & 0 & 117 & 0 & 78 & 50 & 83 & 309 & 216 & 221 \\
\hline 5 & 0 & 0 & 77 & 0 & 67 & 71 & 63 & 240 & 227 & 205 \\
\hline 6 & 0 & 0 & 87 & 0 & 84 & 85 & 84 & 345 & 147 & 134 \\
\hline 7 & 0 & 0 & 129 & 0 & 59 & 65 & 45 & 330 & 155 & 330 \\
\hline 8 & 0 & 0 & 78 & 0 & 52 & 44 & 64 & 176 & 231 & 186 \\
\hline 9 & 0 & 0 & 77 & 0 & 80 & 92 & 21 & 209 & 145 & 260 \\
\hline 10 & 0 & 0 & 97 & 0 & 70 & 73 & 62 & 275 & 345 & 178 \\
\hline 11 & 0 & 0 & 74 & 0 & 125 & 54 & 65 & 150 & 230 & 338 \\
\hline 12 & 0 & 0 & 115 & 0 & 77 & 50 & 41 & 165 & 371 & 196 \\
\hline 13 & 0 & 0 & 98 & 0 & 92 & 31 & 105 & 228 & 221 & 236 \\
\hline 14 & 0 & 0 & 114 & 0 & 98 & 109 & 50 & 185 & 297 & 242 \\
\hline 15 & 0 & 0 & 90 & 0 & 100 & 54 & 82 & 265 & 228 & 269 \\
\hline 16 & 0 & 0 & 103 & 0 & 107 & 83 & 105 & 239 & 229 & 256 \\
\hline 17 & 0 & 0 & 91 & 0 & 98 & 65 & 87 & 320 & 226 & 217 \\
\hline 18 & 0 & 0 & 122 & 0 & 96 & 75 & 80 & 260 & 230 & 259 \\
\hline 19 & 0 & 0 & 86 & 0 & 96 & 98 & 88 & 273 & 146 & 196 \\
\hline 20 & 0 & 0 & 84 & 0 & 97 & 74 & 24 & 401 & 234 & 236 \\
\hline
\end{tabular}

Table 8: Irrigation water volumes (in $\mathrm{mm}$ ) applied to the different crops: Winter Wheat (WW), Winter Barley, (WB), Late Potatoes (LP), Sugar beet (SB), Grain Maize (GM), for the scenarios with irrigation measures and soil and water conservation techniques under current, $\mathrm{Now}^{+}$, and future climatic conditions, Climate Change ${ }^{+}$. 
B.3 Outputs of the economic model: Estimated Risk term

\begin{tabular}{c|c|c|c||c|c} 
& unit & \multicolumn{5}{|c}{ Scenarios } \\
& & Now & Climate Change & Now $^{+}$ & Climate Change $^{+}$ \\
\hline Winter wheat & $€ /$ ha & 60.71 & 70.54 & 74.64 & 104.56 \\
Winter Barley & $€ /$ ha & 69.39 & 0 & 83.75 & 0 \\
Late Potatoes & $€ /$ ha & 410.15 & 222.15 & 576.05 & 455.18 \\
Sugar Beet & $€ /$ ha & 14.54 & -5.23 & 16.29 & -17.65 \\
Grain Maize & $€ /$ ha & 32.63 & 26.90 & 74.32 & 0
\end{tabular}

Table 9: Risk term for the different crops and climate scenarios.

\section{B.4 Supplementary data}




\begin{tabular}{c|c|c|c|c|c} 
& Winter wheat & Winter Barley & Late Potatoes & Sugar Beet & Grain Maize \\
\hline Year 1 & 16.54 & 15.29 & 3.11 & 3.88 & 13.76 \\
Year 2 & 12.05 & 11.8 & 9.54 & 4.2 & 14.59 \\
Year 3 & 11.41 & 10.66 & 8.8 & 4.35 & 14.15 \\
Year 4 & 11.79 & 10.7 & 4.04 & 4.19 & 13.33 \\
Year 5 & 10.64 & 10.27 & 4 & 4 & 12.1 \\
Year 6 & 9.49 & 9.12 & 7.94 & 4.54 & 11.26 \\
Year 7 & 10.2 & 10.2 & 5.86 & 3.79 & 11.28 \\
Year 8 & 9.1 & 8.6 & 4.2 & 4.16 & 10.46 \\
Year 9 & 10.48 & 9.77 & 9.2 & 4.4 & 9.64 \\
Year 10 & 8.89 & 8.26 & 3.99 & 3.96 & 9.2 \\
Year 11 & 10.57 & 9.64 & 13.77 & 3.81 & 7.88 \\
Year 12 & 8.82 & 8.57 & 2.62 & 3.74 & 8.76 \\
Year 13 & 8.53 & 9.2 & 9.13 & 3.91 & 8.32 \\
Year 14 & 11.2 & 9.75 & 13.78 & 3.26 & 8.76 \\
Year 15 & 18.63 & 17.59 & 8.18 & 2.81 & 11.39 \\
Year 16 & 15.3 & 14.5 & 9.62 & 2.63 & 14.9 \\
Year 17 & 9.04 & 8.11 & 6.07 & 2.56 & 12.7 \\
Year 18 & 16.84 & 16.14 & 13.63 & 2.75 & 11.39 \\
Year 19 & 17.53 & 17.62 & 2.54 & 3.63 & 15.94 \\
Year 20 & 21.96 & 22.2 & 20.12 & 4.38 & 19.27
\end{tabular}

Table 10: Prices of Winter Wheat, Winter Barley, Late Potatoes, Sugar beet, Grain Maize for the period 1993-2012. 


\begin{tabular}{ccrrrrr} 
Model Scenario & & WW & WB & LP & \multicolumn{1}{c}{ SB } & \multicolumn{1}{c}{ GM } \\
& WW & 106830,14 & 115303,38 & 324010,71 & 5286,69 & 73219,45 \\
& WB & 115303,38 & 130336,37 & 382655,9 & 15843,05 & 83467,88 \\
Now & LP & 324010,71 & 382655,9 & 3998475,01 & $-17042,02$ & 72100,77 \\
& SB & 5286,69 & 15843,05 & $-17042,02$ & 141471,11 & 16348,37 \\
& GM & 73219,45 & 83467,88 & 72100,77 & 16348,37 & 98969,05 \\
\hline \multirow{5}{*}{ Now } & WW & 141223,14 & 150163,74 & 343167,66 & 9636,47 & 132910,91 \\
& WB & 150163,74 & 165776,04 & 395446,93 & 23942,48 & 150014,2 \\
& LP & 343167,66 & 395446,93 & 5412411,85 & $-87399,48$ & 312540,64 \\
& SB & 9636,47 & 23942,48 & $-87399,48$ & 186399,86 & 40895,93 \\
& GM & 132910,91 & 150014,2 & 312540,64 & 40895,93 & 220012,16 \\
\hline WW & 167698,2 & 147043,05 & 206257,25 & $-51632,01$ & 65795,03 \\
& WB & 147043,05 & 149736,98 & 264436,08 & $-45182,71$ & 68661,63 \\
& LP & 206257,25 & 264436,08 & 3146547,51 & 1528,4 & 60820 \\
& SB & $-51632,01$ & $-45182,71$ & 1528,4 & 208469,06 & $-22169,56$ \\
& GM & 65795,03 & 68661,63 & 60820 & $-22169,56$ & 82586,11 \\
\hline \multirow{2}{*}{ Climate Change ${ }^{+}$} & LP & 491818,94 & 465813,69 & 6175615,46 & $-18567,87$ & 234855,52 \\
& WB & $-90098,34$ & $-84849,74$ & $-18567,87$ & 280254,4 & $-39091,42$ \\
& GM & 124460,8 & 109336,05 & 234855,52 & $-39091,42$ & 121975,93
\end{tabular}

Table 11: Variance-covariance matrix $\Sigma_{g}$ of unitary gross margins for the crop activities and different model scenarios. 


\begin{tabular}{c|c|c|c|c|c|c|} 
& $\mathbf{2 0 0 9}$ & $\mathbf{2 0 1 0}$ & $\mathbf{2 0 1 1}$ & $\mathbf{2 0 1 2}$ & $\mathbf{2 0 1 3}$ & $\mathbf{2 0 1 4}$ \\
Winter wheat & $-0,93$ & 0,91 & $-0,97$ & 1,39 & $-0,47$ & 0,41 \\
Winter barley & 1,5 & $-0,81$ & $-1,02$ & $-0,62$ & $-0,5$ & $-0,94$ \\
Late potato & $-0,93$ & 0,71 & 0,43 & $-1,32$ & $-0,17$ & 1,41 \\
Sugar beet & 0,73 & $-0,43$ & 0,75 & 0,3 & $-0,21$ & $-0,47$ \\
Grain maize & $-0,38$ & $-0,39$ & 0,8 & 0,24 & 1,34 & $-0,42$
\end{tabular}

Table 12: Error terms per crop per observation year. 